\title{
Remote sensing of environmental risk factors for malaria in different geographic contexts
}

\author{
Andrea McMahon ${ }^{1}$, Abere Mihretie ${ }^{2}$, Adem Agmas Ahmed ${ }^{3}$, Mastewal Lake ${ }^{4}$, Worku Awoke ${ }^{5}$ and \\ Michael Charles Wimberly ${ }^{1 *}$ (])
}

\begin{abstract}
Background: Despite global intervention efforts, malaria remains a major public health concern in many parts of the world. Understanding geographic variation in malaria patterns and their environmental determinants can support targeting of malaria control and development of elimination strategies.

Methods: We used remotely sensed environmental data to analyze the influences of environmental risk factors on malaria cases caused by Plasmodium falciparum and Plasmodium vivax from 2014 to 2017 in two geographic settings in Ethiopia. Geospatial datasets were derived from multiple sources and characterized climate, vegetation, land use, topography, and surface water. All data were summarized annually at the sub-district (kebele) level for each of the two study areas. We analyzed the associations between environmental data and malaria cases with Boosted Regression Tree (BRT) models.

Results: We found considerable spatial variation in malaria occurrence. Spectral indices related to land cover greenness (NDVI) and moisture (NDWI) showed negative associations with malaria, as the highest malaria rates were found in landscapes with low vegetation cover and moisture during the months that follow the rainy season. Climatic factors, including precipitation and land surface temperature, had positive associations with malaria. Settlement structure also played an important role, with different effects in the two study areas. Variables related to surface water, such as irrigated agriculture, wetlands, seasonally flooded waterbodies, and height above nearest drainage did not have strong influences on malaria.

Conclusion: We found different relationships between malaria and environmental conditions in two geographically distinctive areas. These results emphasize that studies of malaria-environmental relationships and predictive models of malaria occurrence should be context specific to account for such differences.
\end{abstract}

\section{Introduction}

According to the United Nations Sustainable Development Goals (SDGs), combatting diseases, including mosquito borne diseases such as malaria, is a high priority. In particular, malaria is the focus of ongoing efforts toward

\footnotetext{
*Correspondence: mcwimberly@ou.edu

${ }^{1}$ Department of Geography and Environmental Sustainability, University of Oklahoma, Norman, OK, USA
}

Full list of author information is available at the end of the article control and elimination [1-4]. There has been significant progress in reducing the burden of malaria, but it remains a major public health concern with 229 million malaria cases and 409,000 malaria deaths globally in 2019 [5]. The goal is to reduce these numbers by enabling access to prevention, diagnostic testing and treatment for all people [6]. However, global funding to achieve these goals is limited $[7,8]$. It is essential to use available resources efficiently by spatially targeting prevention, control, and elimination efforts. Therefore, identifying areas with high 
risk of disease transmission is crucial when responding to disease outbreaks, and knowing what environmental factors drive spatial and temporal patterns of disease risk can aid in identifying disease hotspots [9-12].

Mosquito borne diseases, such as malaria, are highly sensitive to environmental conditions. Mosquito life history traits like longevity, fecundity, and biting rates are highly influenced by temperature [13] and humidity $[14,15]$. The rate of pathogen development inside the mosquito (extrinsic incubation period) and transmission probabilities between human and mosquito are also influenced by temperature [13]. Larval habitats, and therefore mosquito abundance, are influenced by land cover [16, 17], hydrological setting [18] and water management for irrigation [19]. All of these factors determine the receptivity of an ecosystem, defined as its potential to support vector mosquitoes and malaria transmission cycles [20]. Receptivity is also affected by the susceptibility of humans to malaria, which depends on their exposure to mosquito bites and access to resources for malaria prevention and treatment. In addition, the vulnerability of a location to malaria is defined as the rate at which parasites are imported through movement of humans or mosquitoes from endemic areas [20].

The increasing availability of very-high resolution satellite data and long-term satellite records provides new opportunities for malaria research [21]. The use of geospatial environmental data to study the risk of diseases, including those transmitted by mosquitoes, has greatly expanded in recent decades [22, 23]. Satellite imagery enables the continuous monitoring of environmental conditions over large areas. The large number of available sensors allows us to measure a wide range of environmental factors that influence malaria receptivity, including meteorological factors such as temperature, humidity, and precipitation as well as landscape features related to land use, vegetation, surface water, and terrain [21]. Long-term records from moderate resolution sensors such as MODIS (1 km spatial resolution) have been used to study the influences of climate variation on seasonal and interannual variations in malaria [24, 25]. Data from high-resolution sensors such as Landsat (30 $\mathrm{m}$ spatial resolution) have been used to assess the effects of water, land cover, and land use on spatial patterns of mosquito vectors [26] and malaria cases [27-29]. Very-high resolution imagery from commercial satellites such as GeoEye ( $0.5 \mathrm{~m}$ spatial resolution) has been used to map individual households [30], and SPOT imagery (1.5 $\mathrm{m}$ spatial resolution) has been used to map larval habitats [31] in support of malaria research and control efforts. Thus, remote sensing is a useful tool for studying the effects of environmental conditions on mosquito borne diseases like malaria [24, 32-35]. In Ethiopia, such studies have established relationships between malaria risk and remotely-sensed environmental factors, such as land surface temperature [33, 36, 37], precipitation [36, 38], greenness and moisture indices [33], wetland cover [27], and distance to water bodies [36].

Identifying the environmental risk factors for malaria is challenging because malaria-environment relationships are heterogeneous across different geographic settings [39]. For example, the influence of rainfall on malaria cases in the Amazon varied between wetlands and upland regions [40], and the seasonal effects of rainfall on malaria vector larvae in Tanzania depended on the type of water body and its geomorphological setting [18]. In the Amhara region of Ethiopia, yearly fluctuations in malaria cases were influenced more by temperature in wetter climates and by precipitation and other variables sensitive to soil moisture in drier locations [41]. The accuracy of climate-driven models of malaria can be improved by identifying groups of locations that have similar climate sensitivities data and fitting a separate model for each group [24].

Malaria-environment relationships are also sensitive to spatial scale. In Ethiopia, spatial analyses of malaria often use case data that are aggregated by district (woreda) [42, 43], including several previous studies relating malaria cases to environmental risk factors [24, 44]. However, woredas vary considerably in size (from $<1 \mathrm{~km}^{2}$ in cities to $>10,000 \mathrm{~km}^{2}$ in some rural areas) and encompass varied climate, topography, and population density. Research conducted at the individual household level shows that overall malaria prevalence varies considerably between households $[45,46]$, as do the distributions of $P$. falciparum and P. vivax [47]. However, these householdbased studies are typically limited to a few villages or to a sample of households across a larger region.

The goal of this study was to assess the potential for using satellite remote sensing data to quantify malaria receptivity across two study sites in Ethiopia. We considered a wide range of variables derived from moderate, high, and very high-resolution satellite imagery that measured climate variation, land cover and land use, surface water dynamics, and human settlements. The study used a malaria surveillance dataset that was aggregated at the scale of sub-district administrative units called kebeles. These are the smallest administrative units in Ethiopia and are important for the planning and implementation of malaria interventions. Previous research has shown that there is considerable kebele-level variation of malaria prevalence within the same district in the Amhara [48] and Oromia [46] regions of Ethiopia. Specific objectives were to identify the remotely sensed variables that were most effective at predicting spatial and interannual variability of malaria cases at the kebele 
level and to determine whether these relationships varied between two distinctive geographic settings.

\section{Methods}

\section{Study area}

Our study area covers four woredas in the Amhara region of Ethiopia that were selected because they were part of a malaria elimination demonstration project to enhance surveillance at sub-district levels (Fig. 1). The Amhara region is located in northwestern Ethiopia and is geographically very diverse. Elevation ranges from 500 to $4500 \mathrm{~m}$. Climate is very seasonal with a pronounced dry season (January-April), rainy season (May-August) and a transition season (September-December). Average monthly rainfalls in Ethiopia ranges from $15 \mathrm{~mm}$ in January to $200 \mathrm{~mm}$ in July [49]. The four woredas are located in two separate areas with distinctive environmental characteristics. To explore how different environmentmalaria relationships depended on geographic context, we studied each area individually.

The first study area, encompassing Mecha and Bahir Dar Zuria, is located south of Lake Tana and the city of Bahir Dar in central Amhara. Elevations range from $1500 \mathrm{~m}$ to $3200 \mathrm{~m}$, mean daily temperatures range from
$16{ }^{\circ} \mathrm{C}$ to $26{ }^{\circ} \mathrm{C}$, and annual precipitation is between $1000 \mathrm{~mm}$ and $2000 \mathrm{~mm}$. The northern section is relatively flat with large expanses of mixed agriculture and extensive wetlands, transitioning to the foothills of the Choke Mountains in the southern section. This study area contains a substantial area of irrigated agriculture within the Koga irrigation development project. The Koga project encompasses two dams with respective water detention ponds and water storage reservoirs. It irrigates 7004 ha of farmland via a system of canals [50].

The second study area, encompassing Aneded and Awabel, is located on the southern edge of the Amhara region between the Choke Mountains to the north and the Blue Nile River to the south. Elevations range from $1000 \mathrm{~m}$ to $3600 \mathrm{~m}$, mean daily temperatures range from $15{ }^{\circ} \mathrm{C}$ to $28{ }^{\circ} \mathrm{C}$, and annual precipitation is between 900 and $1300 \mathrm{~mm}$. This northern section has gradually sloping terrain and is covered by a mosaic of croplands and wetlands, while the southern section drops steeply into the Blue Nile Gorge and has some croplands with large areas of bare soil and sparse vegetation. There is no largescale irrigation scheme in this area.

The Amhara region has unstable malaria transmission that results in sporadic localized and regional outbreaks

\section{Study area}

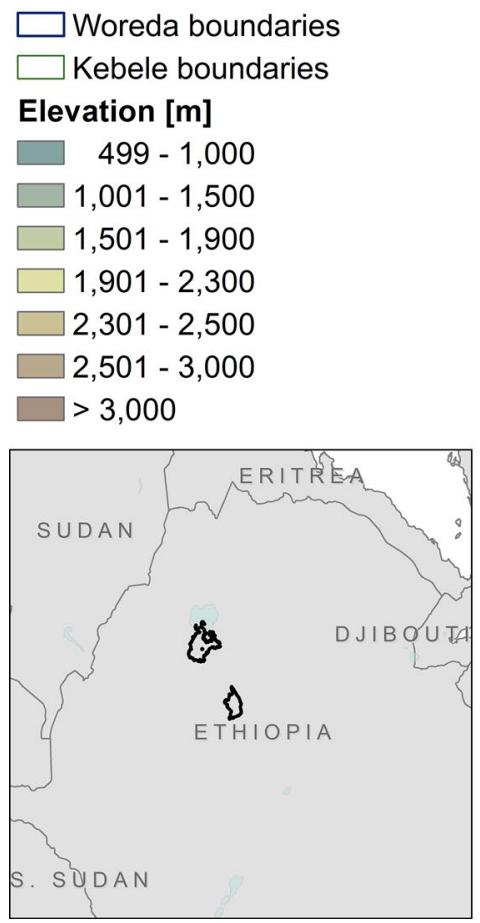

Fig. 1 Study area in the Amhara region of Ethiopia. The left map shows the two study areas within the greater geographic area. The right map shows the two study areas and the topography of the area. Blue lines indicate woredas (district) boundaries, green lines indicate the kebeles within those woredas

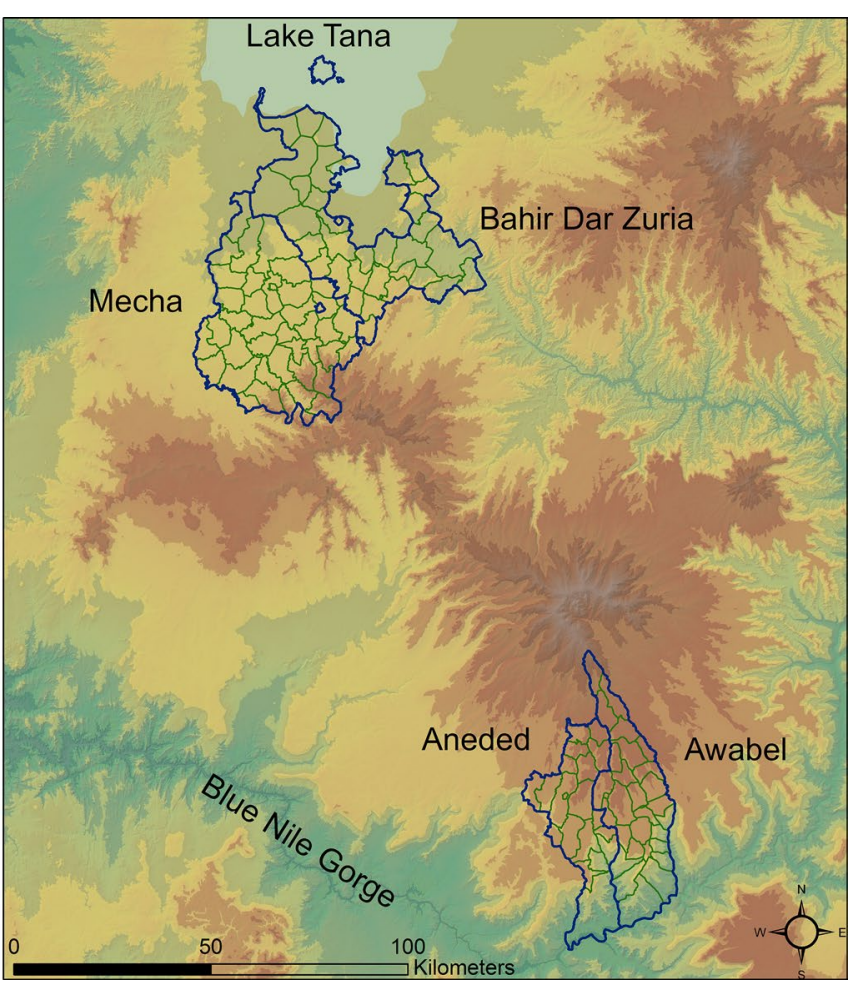


[51]. Outbreaks occur primarily between September and December. The malaria parasites in this region are Plasmodium falciparum and Plasmodium vivax [47] and the primary vector species in this region is the mosquito Anopheles arabiensis [52]. The Ethiopian government is committed to move towards nationwide malaria elimination by 2030 [53]. Due to successes of malaria control efforts, malaria incidence and mortality rates have been declining in the Amhara region [42] and in other parts of Ethiopia [5]. In Ethiopia, malaria surveillance data are usually reported from health facilities and then aggregated by woredas. As part of a malaria elimination pilot project, malaria data from the four woredas were tracked at the kebele level from 2013 to 2018. Kebeles are the smallest administrative unit in Ethiopia, with areas of kebeles for the entire country ranging from $0.1 \mathrm{~km}^{2}$ to $9500 \mathrm{~km}^{2}$ The average size is $50 \mathrm{~km}^{2}$ with a population of typically a few thousand inhabitants [54]. Each kebele has at least one health post that serves up to 5,000 people. Larger kebeles have health centers that serve 20,000 people. Our study area includes a total of 122 kebeles from the four study woredas: Mecha, Bahir Dar Zuria, Aneded and Awabel.

\section{Malaria data}

Malaria case data were collected at local health posts and health centers, summarized by week for each kebele, and reported to the Amhara Regional Health Bureau. The data included malaria cases of patients who sought care at a health post or health center. As per national malaria guidelines, all suspected malaria cases at all health facilities were confirmed by multi species rapid diagnostic tests (at rural health posts) or Giemsa based microscopy (at hospitals and health centers). Weekly summaries included information on the malaria-causing pathogen (total P. falciparum cases, P. vivax cases, and mixed infections), age of the patients (above or below 5 years of age), the number of malaria patients with a travel history, and the number of total outpatients seeking care during a given week.

Because no recent population data were available at the kebele level, we calculated the proportion of outpatients diagnosed with malaria (hereafter referred to as malaria proportion). This ratio is considered a reliable indicator of malaria burden because it controls for temporal variation in health facility attendance, can be calculated in situations where accurate population data are not available [55], and has been used as a measure of malaria burden in previous studies [56-58]. Although global population datasets like WorldPop [59] and LandScan [60] are also available, we decided not to use them because we were not able to validate their accuracy and the kebele level within out study area.
The case data ranged from September 2013 to July 2018. However, we only used data from 2014 to 2017, as these were available for the entire year. Out of 472 reporting health posts or health centers, we did not have reliable location data for six. Together, these six reported only 23 malaria cases for the entire time frame and their exclusion was not expected to influence the results.

Epidemiological data were summarized for all health posts within a kebele and for each year to produce a kebele-wide annual tally of total malaria cases. For treatment and reporting purposes, malaria cases are grouped into two categories: (1) P. falciparum plus mixed infections, (2) P. vivax only. We additionally summarized total malaria cases. To detect statistically significant spatial clusters in malaria occurrence, we performed a scan statistic using SaTScan software version 9.6 [61]. We ran a retrospective purely spatial discrete Poisson model with total outpatients as the population at risk. The scan statistic was performed with an elliptical window for each year and each malaria pathogen group (total malaria cases, $P$. falciparum + mixed cases, and $P$. vivax cases) separately. After determining the spatial clusters for each year, we then identified stable hot spots (areas with recurring clusters in three or four years), unstable hot spots (clusters in one or two years), and areas that were never identified as clusters. More details on the SaTScan analysis can be found in "Additional file 1".

\section{Environmental variables}

Two types of explanatory environmental variables were used to investigate malaria case patterns: dynamic and static variables (Table 1). Dynamic variables included environmental conditions that were expected to vary between and within years, such as land surface temperature and remotely sensed greenness and moisture indices. Static variables included variables related to land cover, land use, and physiography that were not expected to vary substantially from year to year. All satellite data were reprojected to UTM zone 37 before we calculated zonal summaries for each kebele. Maps of summaries of selected variables are shown in Fig. 2. Additional baseline maps of land cover, settlements, and topography can be found in "Additional file 2".

Temperature data were derived from the MODIS Terra Land Surface Temperature and Emissivity Product (MOD11A2) [62]. These data have a spatial resolution of $1 \mathrm{~km}$ and are provided as 8-day composites. We used daytime observations to reduce the problem of missing data from nighttime clouds. Data were filtered using the quality assurance flags to only include observations with an average LST error of below $2{ }^{\circ} \mathrm{K}$. Temperature values were then converted to ${ }^{\circ} \mathrm{C}$. 
Table 1 List of static and dynamic variables used to predict malaria proportion

\begin{tabular}{|c|c|c|c|c|}
\hline Type & Description & Source & Name & Units \\
\hline \multirow[t]{5}{*}{ Dynamic variables } & Daytime temperature & Terra MODIS & LST & ${ }^{\circ} \mathrm{C}$ \\
\hline & Annual rainfall & IMERG & PREC & $\mathrm{mm}$ \\
\hline & Normalized difference vegetation index & MODIS NBAR & NDVI & Index \\
\hline & Normalized difference moisture index & MODIS NBAR & NDMI & Index \\
\hline & Distance to seasonal waterbodies & Landsat OLI & DISTSW & $\mathrm{m}$ \\
\hline \multirow[t]{9}{*}{ Static variables } & Settlement mean density & PlanetScope & SETME & Index \\
\hline & Settlement max density & PlanetScope & SETMX & Index \\
\hline & Area below $2 \mathrm{~m}$ above nearest drainage & DEM, Stream network & HAND & $\%$ \\
\hline & Wetland cover & Midekisa et al. [27] & WETL & $\%$ \\
\hline & Woody vegetation cover & Midekisa et al. [27] & WOODY & $\%$ \\
\hline & Cropland cover & Midekisa et al. [27] & CROP & $\%$ \\
\hline & Open water cover & Midekisa et al. [27] & WATER & $\%$ \\
\hline & Sparse vegetation cover & Midekisa et al. [27] & SPVEG & $\%$ \\
\hline & Irrigation cover & Digitized from Google Earth & |RRI & $\%$ \\
\hline
\end{tabular}

Dynamic variables were summarized for each year for the dry season (_dr), rainy season (_rn), and transition season (_tr)

Spectral indices measuring vegetation greenness and surface moisture were derived from daily $500 \mathrm{~m}$ spatial resolution MODIS Nadir BRDF-Adjusted Reflectance data (MCD43A4) [63]. We applied a data quality filter using the BRDF/Albedo quality product (MCD43A2) and only included observations that were flagged as land and were "good" or "best" quality. We then calculated the Normalized Difference Vegetation Index (NDVI) [64], as well as a Normalized Difference Moisture Index (NDMI) [65].

We imputed missing values and replaced outliers from imperfect cloud-screening using a robust linear regression model from the R MASS library [66]. We fitted a robust linear regression model on our temporal data for NDVI, NDMI, and LST using cyclical splines and estimated outliers with a $z$-score above 3 or below -3 . We then removed observations that were identified as outliers and replaced them, as well as missing values, with predicted values from the robust linear regression model.

Precipitation data were derived from the Integrated Multi-satellitE Retrievals for Global Precipitation Measurement product (IMERG) [67]. IMERG has a spatial resolution of $0.1^{\circ}(\sim 11 \mathrm{~km})$ and a temporal resolution of $30 \mathrm{~min}$. The dynamic variables for land surface temperature, spectral indices, and precipitation were summarized for each kebele and for each season of the year: dry season (January-April), rainy season (May-August), and the transition season (September-December). For each kebele we then calculated the mean seasonal value of each dynamic variable for each year.

Because distance to potential breeding habitat has been identified as risk factor for anopheline mosquito abundance [68], we mapped seasonally flooded areas. We used
$30 \mathrm{~m}$ Landsat 8 Operational Land Imager (OLI) imagery for the dry season and the rainy season of each year. We removed pixels that were flagged as cloud or cloud shadow and calculated the Normalized Difference Water Index (NDWI) [69] for each Landsat scene. To identify seasonally flooded areas, we extracted areas where the median NDWI during the end of the wet season (September-October) was above zero and the median NDWI during the dry season (January-April) was below zero. We then calculated the distance of each pixel to the nearest seasonally flooded pixel, expressed as cumulative cost distance of the shortest path measured in meters from the neatest water source. This was done for each year separately to account for inter-annual variation in flooding extents. Additionally, we added "year" as a continuous variable, to capture inter-annual trends of malaria proportion that are not related to environmental conditions.

Static variables measured environmental conditions that were not expected to change substantially between years. These included data on settlement structures, land cover, and the hydrological setting of the landscape. We created two settlement density indices from $3 \mathrm{~m}$ spatial resolution PlanetScope imagery [70]. We acquired images from November 2016 and classified each tile into building and non-building areas with a Random Forest model using a bag fraction of 0.67 over 500 classification trees. Training data consisted of sampling 7500 points collected from 2000 manually digitized polygons in each study area. The overall accuracy of the building classification based on out-of-bag data was 0.98 for both areas. In Mecha and Bahir Dar Zuria we reached a sensitivity of 0.97 and a specificity of 0.98. In Aneded and Awabel sensitivity and specificity were both 0.98 . To create variables 


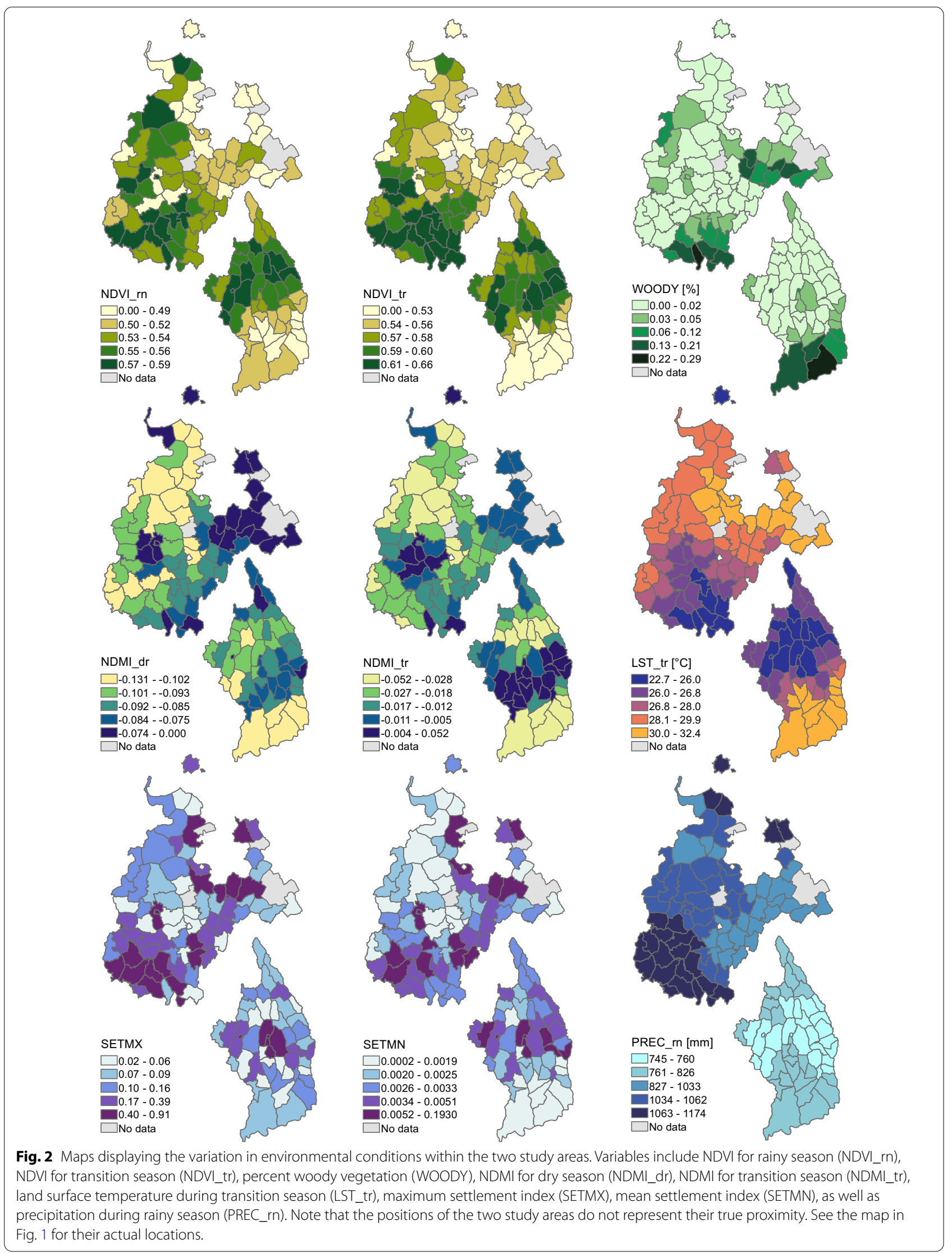


for settlement density, we resampled the classification to $100 \mathrm{~m}$ pixels via a majority filter and then applied a Kernel density estimator using a gaussian kernel with a radius of $100 \mathrm{~m}$ and a sigma of $50 \mathrm{~m}$. For each kebele we summarized the mean and maximum settlement density. Settlement classification and density estimation were performed in Google Earth Engine [71].

To study the impacts of different land cover types on sub-district malaria transmission, we acquired land cover maps from Midekisa et al. [27]. This dataset provides Landsat based classifications of major land cover types in the Amhara region at a $30 \mathrm{~m}$ resolution. It is locally calibrated, and its overall accuracy is reported at $93.5 \%$. We calculated the percentage of each kebele covered by the following land cover classes: open water, herbaceous wetlands, woody vegetation, cropland, and sparse vegetation.

To map areas that are likely to be flooded during larger rain events, we calculated the height above nearest drainage (HAND). The height above nearest drainage measures the vertical distance between a given point and the nearest stream. Low values indicate floodplains and other low-lying areas that are likely to be inundated during and after the rainy season when flow rates are high. We used topographic and stream network data to calculate the HAND using Topography Tools for ArcGIS [72]. We then identified areas less than $2 \mathrm{~m}$ above the nearest drainage and calculated the proportion of each kebele that falls into this category.

\section{Statistical analysis}

We used Boosted Regression Trees (BRT) to model the relationships between malaria cases and environmental variables. BRT models are used in species distribution modeling [73, 74], in epidemiology [75], and to study mosquito borne diseases [32, 76-78]. Advantages of the BRT method are that it yields high accuracy while requiring little tuning [75], performs well under moderate collinearity of predictor variables [79], and captures non-linear relationships between predictor and response variables, and allows for interactions between predictor variables. Poisson BRT models were created using the $R$ library gbm [80].

For each study area, separate models were fitted for $P$. falciparum + mixed cases, $P$. vivax cases, and total cases. Outpatient numbers were included as offset term. The models were fitted with a learning rate of 0.01 , a tree complexity of 3 , and a bag fraction of 0.5 . Several parameter combinations were tested and the combination that yielded the best $R^{2}$ from a fivefold cross validation was selected.

Relative importance of predictor variables was estimated to determine which variables had the strongest influences on malaria patterns. Variable importance is a measure of how often a variable is used to create a split, normalized by the improvement in squared error resulting from the corresponding split. A high variable importance of a variable indicates that the BRT model relied heavily on a specific variable during the model fitting process. It is a common metric to compare the relative influence of predictor variables [74], and has been used to study environmental effects on malaria transmission [32]. We then ranked the variables by their importance value and identified the five most important variables for total malaria cases. To visualize the relationships between these variables and malaria proportion, we fitted partial dependence plots that show how a response variable depends on the predictor variable after taking the average effects of all other variables into account.

\section{Results}

\section{Spatio-temporal patterns in malaria cases}

Between January 2014 and December 2017, a total of 22,584 malaria cases were reported (Table 2). Fiftynine percent of all cases were attributed to $P$. falciparum + mixed, and $41 \%$ of cases were due to P. vivax. In Bahir Dar Zuria and Mecha, P. falciparum + mixed cases made up the largest share of infections, whereas $P$. vivax was more dominant in Aneded and Awabel. Of the four

Table 2 Total malaria case numbers, as well as case number by species, from 2014 to 2017

\begin{tabular}{|c|c|c|c|c|c|c|c|c|}
\hline \multirow[t]{2}{*}{ Woredas } & \multirow{2}{*}{$\begin{array}{l}\text { Total } \\
\text { malaria } \\
\text { cases } \\
\text { Count }\end{array}$} & \multicolumn{2}{|c|}{ P. falciparum + mixed cases } & \multicolumn{2}{|c|}{$P$. vivax cases } & \multicolumn{2}{|c|}{ Traveled cases } & \multirow{2}{*}{$\begin{array}{l}\text { Outpatients } \\
\text { Count }\end{array}$} \\
\hline & & Count & $\%$ of total cases & Count & $\%$ of total cases & Count & $\%$ of total cases & \\
\hline Aneded & 3993 & 2069 & 51.8 & 1924 & 48.2 & 201 & 5.0 & 79,394 \\
\hline Awabel & 6110 & 3436 & 56.2 & 2674 & 43.8 & 592 & 9.6 & 97,052 \\
\hline Bahir Dar Zuria & 6145 & 3767 & 61.3 & 2378 & 38.7 & 257 & 4.1 & 324,769 \\
\hline Mecha & 6336 & 3975 & 62.7 & 2361 & 37.3 & 1058 & 16.7 & 416,009 \\
\hline
\end{tabular}

The number of traveled cases represents all diagnosed malaria cases that indicated a travel history. Outpatient numbers were the total numbers of patients seeking care at health facilities. Outpatient numbers were used to calculate the proportion of outpatients diagnosed with malaria (the malaria proportion) 
woredas, the highest malaria proportion was in Awabel with 62 malaria cases per 1000 outpatients. A total of 2108 cases had a travel history, meaning they left the village for at least one night within the last 30 days. The highest proportion of traveled cases was in Awabel with 6 traveled cases per 1000 outpatients.

From 2014 to 2017, we identified a clear downward trend in total malaria cases for Mecha and Bahir Dar Zuria (Fig. 3). Case numbers in Aneded and Awabel remained more stable over the study period. This led to case numbers in Mecha and Bahir Dar Zuria being higher than those in Aneded and Awabel during 2014 and 2015, but lower in 2016 and 2017. Both study areas showed strong seasonality with low case occurrence between January and April, a small case peak during May-August and most cases occurring during September-December.

There was considerable variation in total malaria proportion within woredas, as well as for cases broken up into the two pathogen groups P. falciparum + mixed and P. vivax (Fig. 4). In Mecha and Bahir Dar Zuria, there was a high malaria proportion in the hilly southern part of the study area, as well as in the flatter central area. In Aneded and Awabel there was a much stronger spatial gradient in malaria proportion with southern kebeles on the Blue Nile escarpment showing a higher malaria proportion. In Mecha and Bahir Dar Zuria, P. vivax was more confined to the kebeles in the southern hills, whereas P. falciparum cases were largely responsible for the central cluster. In Aneded and Awabel, P. falciparum malaria proportion was highest in the kebeles along the Blue Nile escarpment in the south, whereas infections from $P$. vivax cases had additional clusters in the northern and western kebeles. Most cases with a travel history were recorded in the southern hills of Mecha and on the Blue Nile escarpment in Aneded and Awabel. High malaria proportion was correlated with a high proportion of cases with a travel history. The Spearman rank correlation coefficient between travel proportion and $P$. falciparum proportion was 0.6 for Mecha and Bahir Dar Zuria, and 0.62 for Aneded and Awabel. The correlation between travel proportion and $P$. vivax proportion was 0.58 for Mecha and Bahir Dar and 0.54 for Aneded and Awabel.

These general patterns were consistent with the results from the SaTScan analysis (Fig. 5). The kebeles in southern and central Mecha and Bahir Dar Zuria that showed a high malaria proportion over the entire time period were identified as stable malaria hotspots with malaria clusters in at least 3 years. Similarly, in Aneded and Awabel, areas with overall high malaria proportion were found to be stable malaria hotspots with clusters identified for every year. The SaTScan results showed that the high malaria proportion in the southern kebeles of both zones were due to consistent annually recurring outbreaks and not due to individual large outbreaks. Notably, in Aneded and Awabel most kebeles were either identified as stable hotspots for $P$. falciparum with clusters in three or four years, or as areas that were never identified as hotspots. Only very few kebeles were identified as unstable $P$. falciparum hotspots with clusters in one or two years. $P$. vivax case clusters in Aneded and Awabel were less stable with a considerable number of kebeles being identified as clusters in one or two years.

\section{Association between malaria and environmental variables} We compared model performance metrics for BRT models for each study area and malaria species, as well as total cases. The cross-validated $\mathrm{R}^{2}$ values were higher in Aneded and Awabel with 0.90 for total cases, 0.91 for P. falciparum and mixed cases, and 0.78 for P. vivax cases. In Mecha and Bahir Dar Zuria, the cross-validated
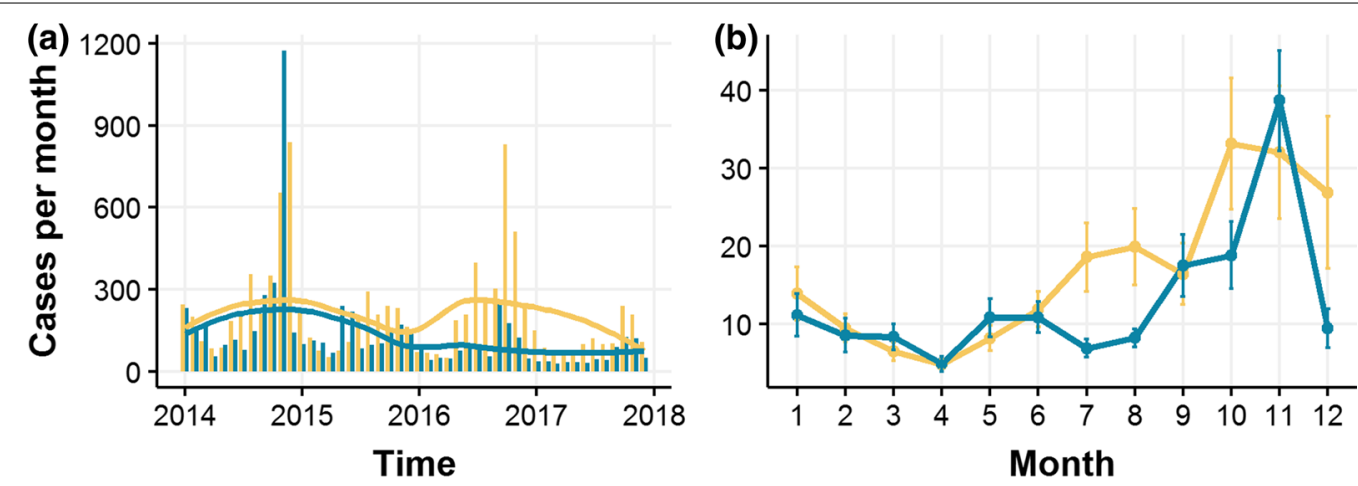

Study area Aneded, Awabel - Mecha, Bahir Dar Zuria

Fig. 3 Total malaria case numbers from Jan 2014-Dec 2017 by study area. a Monthly case numbers shown over entire study period. Lines indicate LOESS smoothed trend. $\mathbf{b}$ Seasonality of total malaria cases. Lines represent mean case numbers over all kebeles and years. Error bars indicate the standard error of the observed mean 

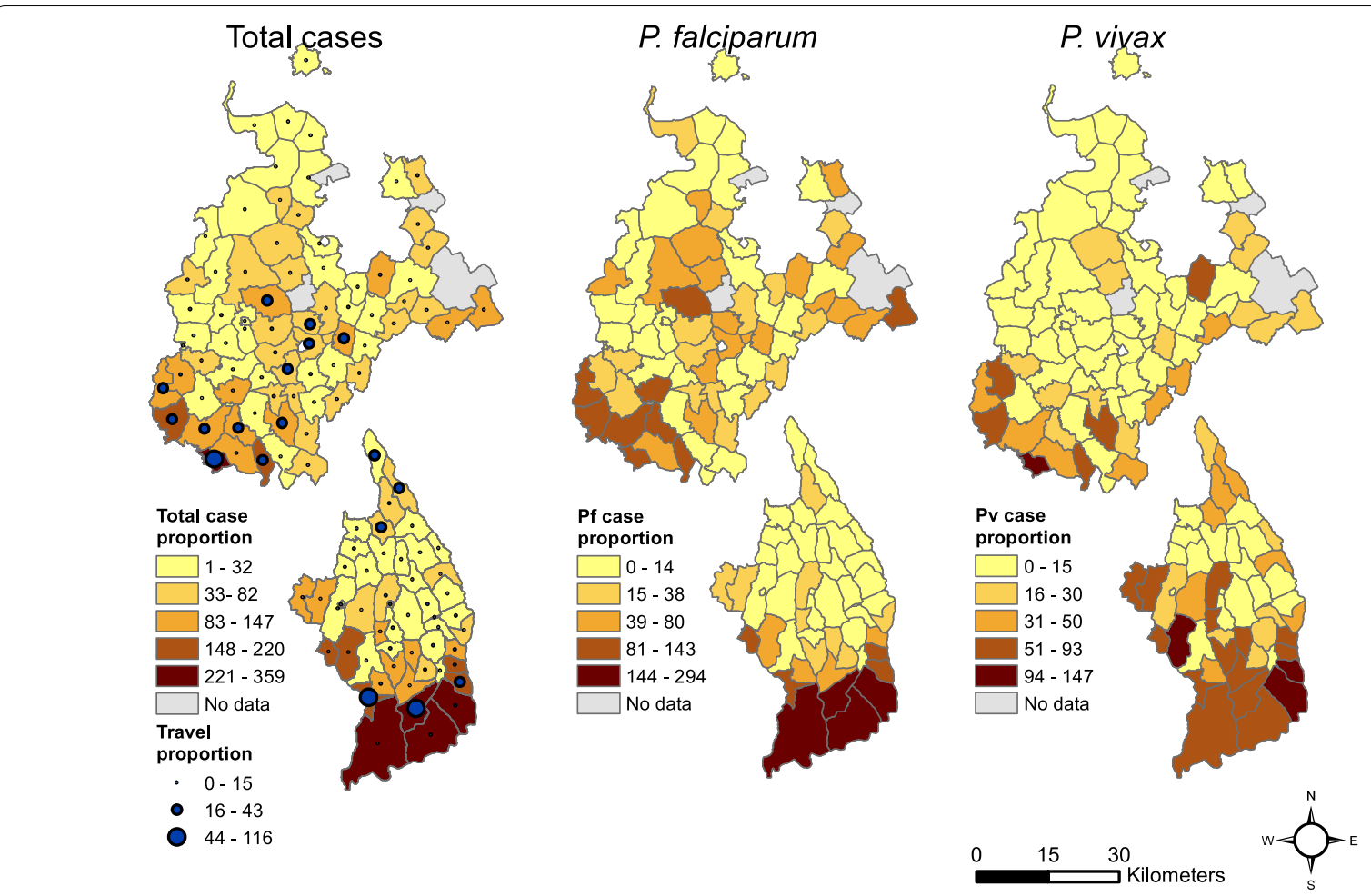

Fig. 4 Spatial distribution of malaria proportion. Malaria proportion is the number out of 1,000 outpatients that were diagnosed with malaria for total malaria cases, P. falciparum + mixed cases, and P. vivax cases. The upper maps are the woredas Mecha and Bahir Dar Zuria, and the lower maps are the woredas Aneded and Awabel. Blue dots indicate the travel proportion, which is the total malaria patients with travel history per 1000 outpatients

$\mathrm{R}^{2}$ values were 0.6 for total cases, 0.54 for $P$. falciparum and mixed cases and 0.68 for P. vivax cases. In Mecha and Bahir Dar Zuria, the cross-validated $\mathrm{R}^{2}$ for $P$. vivax was higher than for $P$. falciparum, whereas in Aneded and Awabel the cross-validated $\mathrm{R}^{2}$ for $P$. falciparum was higher than for P. vivax.

We quantified the relative importance of all variables in the different BRT models and visualized a subset of variables that represent the five most important variables for total malaria cases, as well as the respective partial dependence plots to interpret the influence of environmental variables on malaria proportion (Fig. 6). Tables with all variables and their relative importance scores can be found in the supplement "Additional file 3". The most important variables differed between the two study areas with only NDVI during the transition season appearing in the top five of both study areas and both malaria species. In both study areas at least one of the two seasonal vegetation or moisture indices was important, as well as was at least one settlement density index. Except for \% Woody vegetation, none of the land cover variables contributed substantially to any of the models. None of the hydrological variables, including the distance to seasonal water, height above nearest drainage, or percent of land within the Koga irrigation scheme, were among the most important variables.

In Mecha and Bahir Dar Zuria, all variable importance values were below $20 \%$, indicating that the BRT model relied relatively evenly on a larger number of variables and that no variable stood out in explaining most of the variation on its own. P. falciparum was most strongly influenced by NDVI during the transition season (10\%), with higher malaria proportion coinciding with NDVI values below 0.5. Similarly, NDMI values below -0.01 during the transition season were also associated with a higher malaria proportion. Precipitation above $1,200 \mathrm{~mm}$ during the rainy season was associated with a higher malaria proportion. P. vivax in Mecha and Bahir Dar Zuria was mostly influenced by NDVI during transition season $(17 \%)$ with a higher malaria proportion related to lower NDVI values, and maximum settlement index (13\%) with a higher malaria proportion in kebeles with the highest aggregations of buildings. Year was an important variable for both malaria pathogens in Mecha and Bahir Dar Zuria, indicating that the downward trend over the entire study period was driven by processes not related to environmental factors included in this model. 


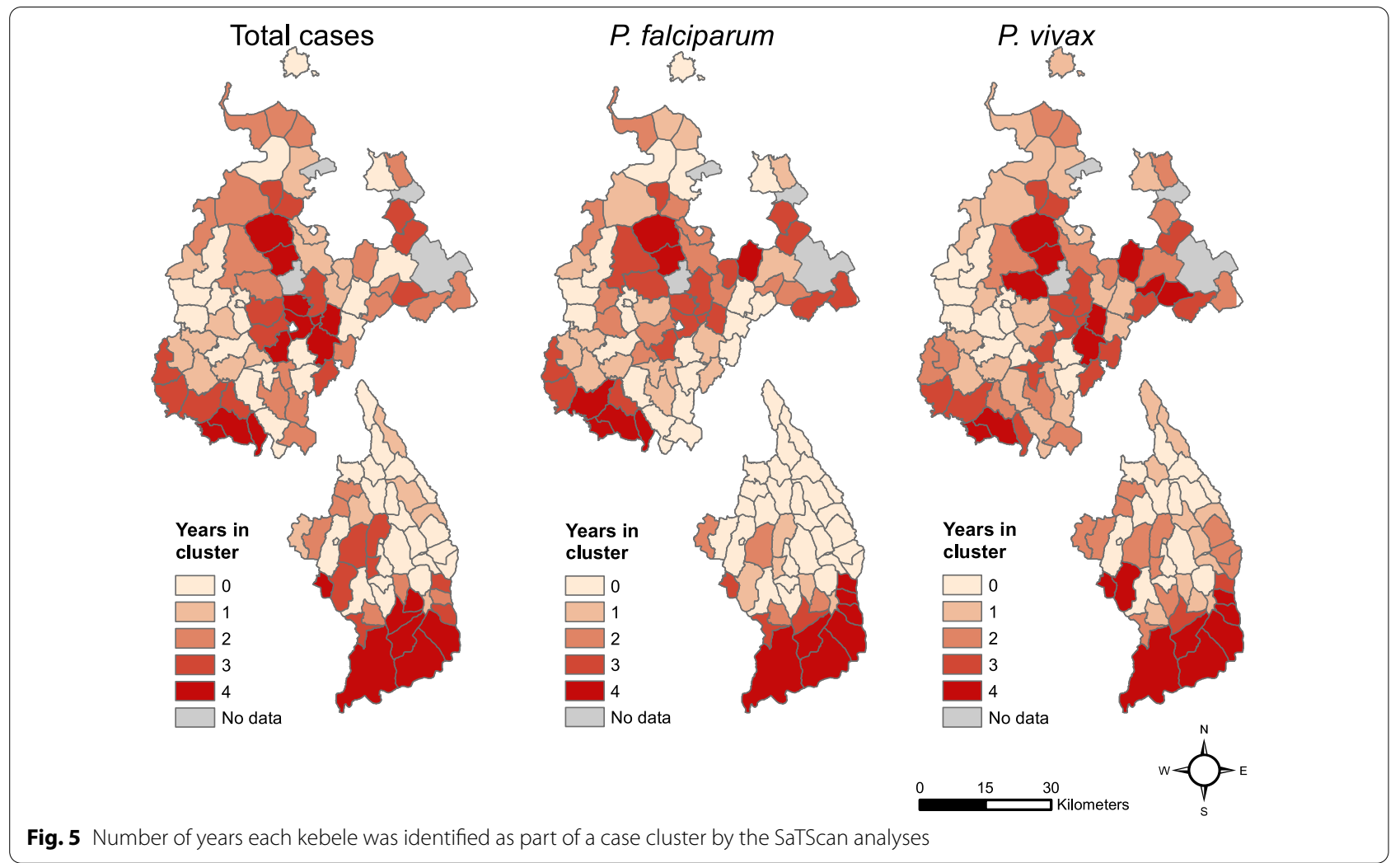

In Aneded and Awabel, NDMI during the dry season was by far the most important variable for both malaria species ( $41 \%$ for $P$. falciparum and $36 \%$ for $P$. vivax). Additionally, NDVI values below 0.55 during transition season were also associated with more malaria for both species (both $<10 \%$ ). Both spectral indices showed associations

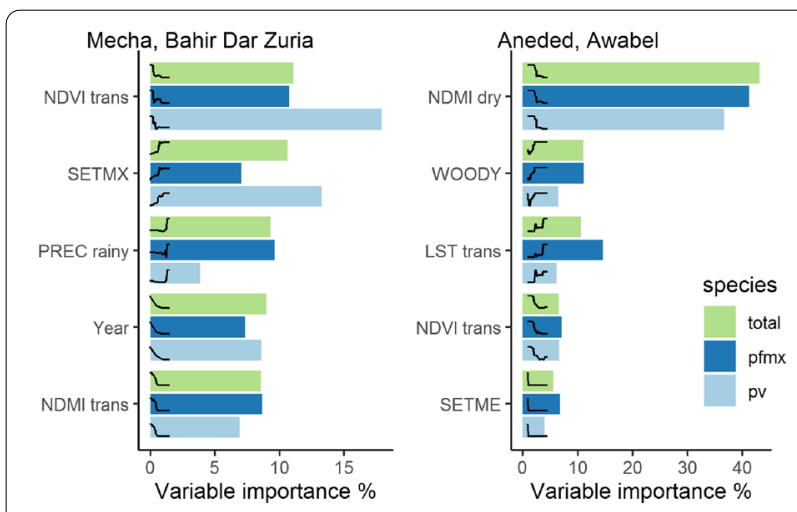

Fig. 6 Variable importance of the five most important environmental variables as identified by boosted regression tree models. Different colored bars represent different malaria species (green $=$ total species, dark blue $=P$. falciparum and mixed infections, light blue $=P$. vivax). Curves represent the fitted partial dependence curve for each variable of drier or less green conditions with malaria occurrence. Higher malaria proportion was also positively associated with percent cover of woody vegetation for $P$. falciparum (11\%), and $P$. vivax (6\%). Mean LST above $25^{\circ} \mathrm{C}$ during transition season had a positive effect on malaria proportion for both species. However, the relative importance of LST for $P$. falciparum and mixed cases (14\%) was larger than for $P$. vivax (6\%). For both species, a mean settlement index of close to zero was associated with a higher malaria proportion (both $<10 \%$ ).

\section{Discussion}

This study presents a kebele-level analysis of malaria occurrence in the Amhara region in Ethiopia between 2014 and 2017. Remotely sensed environmental variables were used to explore the influences of environmental risk factors. We found considerable small-scale variation in the proportion of outpatients with malaria and malaria case clusters among the kebeles of each study area. Climatic variables, settlement structure, and spectral indices were associated with malaria risk, whereas variables related to seasonal waterbodies, flood plains, and irrigation had weaker relationships. However, the relative importance of the variables, as well as the association between those variables and malaria, varied between the two study areas, as well as between the different 
Plasmodium species. These results support the findings of previous studies that there is geographic variation in the relationships between environmental conditions and malaria.[18, 24, 40,41] and highlights the importance of stratifying disease risk models into zones with similar geographic context when studying large, heterogeneous areas [24].

In Mecha and Bahir Dar Zuria, the malaria cases varied along a precipitation gradient, with the highest malaria risk in areas with the most rainfall. This effect is not surprising, as the association of malaria with climatic factors, including rainfall, has been well established in the area $[33,36,38]$. The negative associations with NDVI and NDMI values during transition season could be an indicator of available breeding sites for $A n$. arabiensis. Areas that received heavy rainfall during the rainy season, but had drier conditions during the transition season, could have more isolated pools as surface water recedes. Such areas have been found to be favorable breeding sites for An. arabiensis [81]. Additionally, a high vegetation cover can create unfavorable conditions for An. arabiensis, which prefers sun-lit pools with low vegetation cover [82]. The positive influence of maximum settlement index indicates that kebeles where buildings are aggregated into one or more settlements are at higher risk than kebeles where dwellings are dispersed throughout the countryside.

In Aneded and Awabel, the malaria proportion was primarily associated with low NDMI values during the dry season. These dry areas are also located on the Blue Nile escarpment, which is the most isolated and sparsely settled part of this study area. In addition to the mosquito habitat associations discussed for Mecha and Bahir Dar Zuria, the negative influences of NDMI on malaria in Aneded and Awabel could also reflect underlying socioeconomic factors. For example, there is a relationship between the risk of getting infected with malaria and the main source of water of a household, with households that need less time to access water being at lower risk than households that require more time to access water [83]. This effect may be amplified in drier environments with less water availability. Additionally, the driest kebeles in this region are sparsely settled, as reflected in the negative association between mean settlement index and malaria. Further, the terrain of the escarpment is steep and rugged and is isolated from major highways and cities. Households on the escarpment may have difficulties in accessing resources known to reduce infection risk, such as information about malaria treatment [84], bed nets [85], and other malaria prevention tools [86], resulting in higher susceptibility to malaria infections.

Land surface temperature was found to be the second strongest predictor of P. falciparum in Aneded and
Awabel. However, it was less important in predicting $P$. vivax distribution. Previous research has found that due to the different biology of the two parasites, P. falciparum is limited to lower elevations with warmer temperatures, whereas $P$. vivax is more tolerant of lower temperatures and therefore occurs in higher elevations in the Amhara region $[47,87]$. The effects of temperature on $P$. falciparum in Aneded and Awabel may therefore be due to a temperature threshold that is reached in the higher elevations of this study area. Additionally, in other parts of Ethiopia it has been reported that An. arabiensis is mostly prevalent in lower elevations whereas An. cinereus dominates at higher elevations [88]. Because the temperature gradient in Aneded and Awabel follows an elevation gradient, change in the dominant vector species may be an additional explanation of why we see a temperature effect in this region.

In both study areas we found that malaria cases with recorded travel histories were concentrated in certain kebeles, and these kebeles tended to have high $P$. falciparum cases. Travel has been shown to be a significant risk factor for malaria transmission, particularly for $P$. falciparum related infections [89]. In rural areas in Amhara seasonal migrants often leave their village to seek an additional income elsewhere [90]. Migrant workers are often found to have increased exposure to malaria risk due to low bed net utilization, as well as sleeping outside [91]. Migrant workers from rural areas could therefore be a source of repeated pathogen introduction into their home communities. From the available data we could not tell where and for how long they traveled, nor could we derive which Plasmodium species the patients with travel history were infected with. Travel history was therefore not included in our formal analysis. However, these data suggest that vulnerability to imported cases is an important factor that must be considered in addition to local receptivity for malaria transmission. Some of the observed relationships with remotely sensed environmental variables may reflect environmental settings with marginal agriculture where residents are more likely to travel for seasonal employment.

Surface water-related variables did not strongly influence malaria proportion in our model in either of the two study areas. These included the coverage of open water, herbaceous wetlands, percent of land within the Koga irrigation scheme, the average distance to the nearest seasonal waterbody, as well as areas likely to flood due to their height above the nearest drainage. These findings contrast with the general expectation of relationships between malaria cases and temporary water bodies. Other studies from different parts of Ethiopia have found that woredas with high wetland cover had high malaria incidence [27] and household surveys showed that the 
distance to breeding sites for samples of individual households influences malaria risk [38, 92, 93]. However, those previous studies have been performed at different spatial scales, and water-related variables were much less important at the kebele level within the woredas that we studied. Additionally, the water variables were derived from $30 \mathrm{~m}$ Landsat imagery and a $30 \mathrm{~m}$ digital terrain model, and this spatial resolution is unable to capture smaller water bodies that can act as larval habitat.

The presence of the Koga irrigation scheme did not influence malaria cases. The consistent source of water in irrigated areas creates breeding habitat for anopheline mosquitoes, as observed for a comparable large dam project in Ethiopia [94]. The lack of an irrigation effect on malaria in our study may be an example of what Ijumba and Lindsay describe as the "paddies paradox" [95]. There are two possible explanations for this phenomenon in this area. The first factor may be the separation between agricultural land and settlements. The kebeles that are dominated by the Koga irrigation scheme do not have large settlements, as those are located further away in neighboring kebeles that do not have irrigated land cover. Secondly, the Koga irrigation scheme reportedly increased wealth in irrigator households [50]. Increased wealth, better access to health care and education may contribute to a low burden of malaria in this region. Despite high receptivity to malaria because of readily available breeding sites, the spatial separation between irrigation and settlements, in addition to improvements of the socio-economic conditions in the area may have reduced susceptibility and vulnerability of the human population, leading to low malaria cases despite available mosquito habitats.

The utilization of remotely sensed satellite data to study malaria infection patterns comes with limitations. The nature of satellite earth observation data allows us to study the physical properties of the earth surface and measure a variety of factors that influence malaria receptivity. We could not directly measure socio-economic factors like housing, access to health care, and effectiveness of malaria interventions that affect the susceptibility of human populations. In addition, we could not quantify the vulnerability of communities to imported cases. We also could not relate the observed patterns to different species of vector mosquitoes, as entomological data was not available at such a large extent. Particularly in Mecha and Bahir Dar Zuria, the cross-validated $\mathrm{R}^{2}$ values from 0.54 to 0.68 indicate that environmental variables alone cannot explain all of the spatial and interannual variation in malaria cases. The importance of non-environmental factors in this study area is also reflected in the strong downward trend of malaria cases due to the impact of recent intervention programs. Because this study focused on assessing different sources of remotely-sensed environmental data, incorporating these socio-economic factors was outside our scope.

We faced additional limitations in classifying settlements via PlanetScope imagery. The spatial resolution of $3 \mathrm{~m}$ was sufficient to capture agglomerations of buildings, as well as most of the isolated buildings. However, it was not sufficient to capture some smaller huts with thatched roofs. To capture these buildings, imagery with an even higher spatial resolution would be necessary. Additional research on high resolution settlement mapping could also help to improve downscaled population estimates such as those produced by WorldPop [59] and LandScan [60], which would allow local estimates of malaria incidence in addition to the proportion of outpatients diagnosed with malaria.

\section{Conclusion}

Relationships between spatio-temporal patterns of malaria proportion and environmental variables derived from satellite imagery varied in two landscapes in Ethiopia and were different from results of previous malariaenvironment studies conducted at coarser resolution (data summarized at woreda level) and finer (sample households at village level) resolutions. Associations between climate variables and malaria followed the expected pattern with higher temperatures and more rainfall leading to more malaria cases. In both study areas, we found that kebeles with lower vegetation greenness and moisture during the malaria transmission season had the most malaria cases. Malaria was associated with concentrated settlement patterns in one study area, and with low settlement density in the other study area. To some degree, the relationships of these environmental variables with malaria likely reflected indirect relationships with aspects of the social environment such as seasonal migration, water management, and access to health care that affect malaria risk. Recent interventions have lowered malaria incidence and may also have modified some of these malaria-environment associations. These results emphasize that malaria-environment relationships based on remotely sensed environmental indices are contingent on the scale of analysis as well as the geographic setting. Knowledge of the local malaria epidemiology and its connections with physical and human geography is therefore essential for understanding these relationships and applying them to support risk assessment for public health applications. 


\section{Supplementary Information}

The online version contains supplementary material available at https://doi. org/10.1186/s12942-021-00282-0.

Additional file 1: Supplemental methods describing the SaTScan analyses used for cluster detection.

Additional file 2: Supplemental maps of the study areas showing highresolution land cover and terrain.

Additional file 3: Supplemental tables of variable importance for all variables used in each model.

\section{Acknowledgements}

We thank Dr. Justin K. Davis and Dr. Dawn M. Nekorchuk for providing technical help with data analysis.

\section{Authors' contributions}

AnM and MCW conceptualized the study, AAA, ML, WA, AbM acquired the data and contributed to the interpretation of the data. AnM performed the main analysis and drafted the manuscript. All authors read and approved the final manuscript.

\section{Funding}

This work has been supported by the National institute of Allergy and Infectious Diseases (R01-Al079411)

\section{Availability of data and materials}

Satellite data products MODIS, Landsat, and IMGERG data used are publicly available and were accessed via Google Earth Engine (https://code.earth engine.google.com/). PlanetScope data are accessible for researchers via the "Education and Research Program (https://www.planet.com/markets/educa tion-and-research/). Public health data that support the findings of this study are not publicly available, as they were obtained via a data sharing agreement with the Amhara Regional Health Bureau.

\section{Declarations}

\section{Ethics approval and consent to participate}

Not applicable.

\section{Consent for publication}

Not applicable.

\section{Competing interests}

The authors declare that they have no competing interests.

\section{Author details}

'Department of Geography and Environmental Sustainability, University of Oklahoma, Norman, OK, USA. ${ }^{2}$ Health, Development, and Anti-Malaria Association, Addis Ababa, Ethiopia. ${ }^{3}$ Malaria Control and Elimination Partnership in Africa, Bahir Dar, Ethiopia. ${ }^{4}$ Amhara Public Health Institute, Bahir Dar, Ethiopia. ${ }^{5}$ School of Public Health, Bahir Dar University, Bahir Dar, Ethiopia.

Received: 25 February 2021 Accepted: 3 June 2021

Published online: 13 June 2021

\section{References}

1. Tanner M, Greenwood B, Whitty CJM, Ansah EK, Price RN, Dondorp AM, et al. Malaria eradication and elimination: views on how to translate a vision into reality. BMC Med. 2015;13:1-22.

2. Newby G, Bennett A, Larson E, Cotter C, Shretta R, Phillips AA, et al. The path to eradication: a progress report on the malaria-eliminating countries. Lancet. 2016;387:1775-84.

3. Dhiman S. Are malaria elimination efforts on right track? An analysis of gains achieved and challenges ahead. Infect Dis Poverty. 2019;8:14.
4. Talapko J, Škrlec I, Alebić T, Jukić M, Včev A. Malaria: the past and the present. Microorganisms. 2019;7:179.

5. WHO. World malaria report 2020. Geneva; 2020.

6. United Nations. The Millennium Development Goals Report. New York; 2013.

7. Pigott DM, Atun R, Moyes CL, Hay SI, Gething PW. Funding for malaria control 2006-2010: a comprehensive global assessment. Malar J. 2012;11:246.

8. Patouillard E, Griffin J, Bhatt S, Ghani A, Cibulskis R. Global investment targets for malaria control and elimination between 2016 and 2030. BMJ Glob Health. 2017:2:e000176.

9. Bousema T, Griffin JT, Sauerwein RW, Smith DL, Churcher TS, Takken W, et al. Hitting hotspots: spatial targeting of malaria for control and elimination. PLoS Med. 2012:9:e1001165-e1001165.

10. Hay SI, Battle KE, Pigott DM, Smith DL, Moyes CL, Bhatt S, et al. Global mapping of infectious disease. Philos Trans R Soc B Biol Sci. 2013;368:20120250-20120250.

11. Pigott DM, Howes RE, Wiebe A, Battle KE, Golding N, Gething PW, et al. Prioritising infectious disease mapping. PLOS Neglected Trop Dis. 2015:9:e0003756.

12. Cohen JM, Le Menach A, Pothin E, Eisele TP, Gething PW, Eckhoff PA, et al. Mapping multiple components of malaria risk for improved targeting of elimination interventions. Malar J. 2017;16:459.

13. Mordecai EA, Caldwell JM, Grossman MK, Lippi CA, Johnson LR, Neira $\mathrm{M}$, et al. Thermal biology of mosquito-borne disease. Ecol Lett. 2019;22:1690-708.

14. Lunde TM, Korecha D, Loha E, Sorteberg A, Lindtjørn B. A dynamic model of some malaria-transmitting anopheline mosquitoes of the Afrotropical region. I. Model description and sensitivity analysis. Malar J. 2013;12:28.

15. Yamana TK, Eltahir EAB. Incorporating the effects of humidity in a mechanistic model of Anopheles gambiae mosquito population dynamics in the Sahel region of Africa. Parasit Vectors. 2013;6:235.

16. Munga S, Minakawa N, Zhou G, Mushinzimana E, Barrack O-OJ, Githeko AK, et al. Association between land cover and habitat productivity of malaria vectors in western Kenyan highlands. Am J Trop Med Hyg. 2006:74:69-75

17. Debebe Y, Hill SR, Tekie H, Ignell R, Hopkins RJ. Shady business: understanding the spatial ecology of exophilic Anopheles mosquitoes. Malar 」. 2018;17:351.

18. Hardy AJ, Gamarra JGP, Cross DE, Macklin MG, Smith MW, Kihonda J, et al. Habitat hydrology and geomorphology control the distribution of malaria vector larvae in rural Africa. PLoS ONE. 2013:8:e81931.

19. Kibret S, Wilson GG, Tekie H, Petros B. Increased malaria transmission around irrigation schemes in Ethiopia and the potential of canal water management for malaria vector control. Malar J. 2014;13:360.

20. WHO, World Health Organization. A framework for malaria elimination. 2017.

21. Wimberly MC, de Beurs KM, Loboda TV, Pan WK. Satellite observations and malaria: new opportunities for research and applications. Trends Parasitol. 2021;37:525-37.

22. Kazansky Y, Wood D, Sutherlun J. The current and potential role of satellite remote sensing in the campaign against malaria. Acta Astronaut. 2016:121:292-305.

23. Parselia E, Kontoes C, Tsouni A, Hadjichristodoulou C, Kioutsioukis I, Magiorkinis $\mathrm{G}$, et al. Satellite earth observation data in epidemiological modeling of malaria, dengue and West Nile virus: a scoping review. Remote Sens Multidicip Dig Publ Inst. 2019;11:1862.

24. Davis JK, Gebrehiwot T, Worku M, Awoke W, Mihretie A, Nekorchuk $D$, et al. A genetic algorithm for identifying spatially-varying environmental drivers in a malaria time series model. Environ Model Softw. 2019;119:275-84

25. Sewe MO, Tozan Y, Ahlm C, Rocklöv J. Using remote sensing environmental data to forecast malaria incidence at a rural district hospital in Western Kenya. Sci Rep. 2017;7:2589.

26. Adeola AM, Olwoch JM, Botai JO, de Rautenbach CJW, Kalumba AM, Tsela $\mathrm{PL}$, et al. Landsat satellite derived environmental metric for mapping mosquitoes breeding habitats in the Nkomazi municipality, Mpumalanga Province, South Africa. South Afr Geogr J Routledge. 2017;99:14-28.

27. Midekisa A, Senay GB, Wimberly MC. Multisensor earth observations to characterize wetlands and malaria epidemiology in Ethiopia. Water Resour Res. 2014:50:8791-806. 
28. Rakotoarison HA, Rasamimalala M, Rakotondramanga JM, Ramiranirina B, Franchard T, Kapesa L, et al. Remote sensing and multi-criteria evaluation for malaria risk mapping to support indoor residual spraying prioritization in the central highlands of Madagascar. Remote Sens Multidiscip Dig Publ Inst. 2020;12:1585

29. Bui Q-T, Nguyen Q-H, Pham VM, Pham MH, Tran AT. Understanding spatial variations of malaria in Vietnam using remotely sensed data integrated into GIS and machine learning classifiers. Geocarto Int Taylor \& Francis. 2019:34:1300-14.

30. Shields T, Pinchoff J, Lubinda J, Hamapumbu H, Searle K, Kobayashi T, et al. Spatial and temporal changes in household structure locations using high-resolution satellite imagery for population assessment: an analysis of household locations in southern Zambia between 2006 and 2011. Geospat Health. 2016;11:410.

31. Kabaria CW, Molteni F, Mandike R, Chacky F, Noor AM, Snow RW, et al. Mapping intra-urban malaria risk using high resolution satellite imagery: a case study of Dar es Salaam. Int J Health Geogr. 2016;15:26.

32. Solano-Villarreal E, Valdivia W, Pearcy M, Linard C, Pasapera-Gonzales J, Moreno-Gutierrez D, et al. Malaria risk assessment and mapping using satellite imagery and boosted regression trees in the Peruvian Amazon. Sci Rep Nat Publ Group. 2019;9:15173.

33. Midekisa A, Senay G, Henebry GM, Semuniguse P, Wimberly MC. Remote sensing-based time series models for malaria early warning in the highlands of Ethiopia. Malar J. 2012;11:165-165.

34. Machault V, Vignolles C, Borchi F, Vounatsou P, Pages F, Briolant S, et al. The use of remotely sensed environmental data in the study of malaria. Geospat Health. 2011;5:151-68.

35. Ebhuoma O, Gebreslasie M. Remote sensing-driven climatic/environmental variables for modelling malaria transmission in sub-saharan Africa. Int J Environ Res Public Health Multidicip Dig Publ Inst. 2016;13:584.

36. Minale AS, Alemu K. Malaria-risk assessment using geographical information system and remote sensing in Mecha District, West Gojjam. Ethiopia Geospatial Health. 2018;13:157-63.

37. Endo N, Eltahir EAB. Increased risk of malaria transmission with warming temperature in the Ethiopian Highlands. Environ Res Lett IOP Publishing. 2020;15:054006

38. Belay DB, Kifle YG, Goshu AT, Gran JM, Yewhalaw D, Duchateau L, et al. Joint Bayesian modeling of time to malaria and mosquito abundance in Ethiopia. BMC Infect Dis. 2017;17:415-415.

39. Stresman $\mathrm{GH}$. Beyond temperature and precipitation: ecological risk factors that modify malaria transmission. Acta Trop. 2010;116:167-72.

40. Olson SH, Gangnon R, Elguero E, Durieux L, Guégan JF, Foley JA, et al. Links between climate, malaria, and wetlands in the Amazon basin. Emerg Infect Dis. 2009;15:659-62.

41. Midekisa A, Beyene B, Mihretie A, Bayabil E, Wimberly MC. Seasonal associations of climatic drivers and malaria in the highlands of Ethiopia. Parasit Vectors. 2015:8:339.

42. Lankir D, Solomon S, Gize A. A five-year trend analysis of malaria surveillance data in selected zones of Amhara region. Northwest Ethiopia BMC Public Health. 2020;20:1175.

43. Lemma W. Impact of high malaria incidence in seasonal migrant and permanent adult male laborers in mechanized agricultural farms in Metema-Humera lowlands on malaria elimination program in Ethiopia. BMC Public Health. 2020;20:320

44. Merkord CL, Liu Y, Mihretie A, Gebrehiwot T, Awoke W, Bayabil E, et al. Integrating malaria surveillance with climate data for outbreak detection and forecasting: the EPIDEMIA system. Malar J. 2017;16:89.

45. Esayas E, Woyessa A, Massebo F. Malaria infection clustered into small residential areas in lowlands of southern Ethiopia. Parasite Epidemiol Control. 2020;10:e00149.

46. Zemene E, Koepfli C, Tiruneh A, Yeshiwondim AK, Seyoum D, Lee M-C, et al. Detection of foci of residual malaria transmission through reactive case detection in Ethiopia. Malar J. 2018;17:390.

47. Yalew WG, Pal S, Bansil P, Dabbs R, Tetteh K, Guinovart C, et al. Current and cumulative malaria infections in a setting embarking on elimination: Amhara. Ethiopia Malar J. 2017;16:242.

48. Scott CA, Yeshiwondim AK, Serda B, Guinovart C, Tesfay BH, Agmas A, et al. Mass testing and treatment for malaria in low transmission areas in Amhara Region. Ethiopia Malar J. 2016;15:305.

49. Lemma E, Upadhyaya S, Ramsankaran R. Investigating the performance of satellite and reanalysis rainfall products at monthly timescales across different rainfall regimes of Ethiopia. Int J Remote Sens Taylor \& Francis. 2019;40:4019-42.

50. Kassie KE, Alemu BA, Wedajoo AS. Impact of irrigation on household multidimensional poverty reduction in the Koga irrigation development project, northern Ethiopia. Asian Dev Perspect. 2018;9:159-87.

51. Abeku TA, Vlas SJD, Borsboom G, Teklehaimanot A, Kebede A, Olana D, et al. Forecasting malaria incidence from historical morbidity patterns in epidemic-prone areas of Ethiopia: a simple seasonal adjustment method performs best. Trop Med Int Health. 2002;7:851-7.

52. Animut A, Balkew M, Lindtjørn B. Impact of housing condition on indoor-biting and indoor-resting Anopheles arabiensis density in a highland area, central Ethiopia. Malar J. 2013;12:393.

53. Federal Ministry of Health. National malaria elimination strategic plan: 2021-2025. Addis Ababa; 2020

54. Central Statistical Agency. 2007 population and housing census of Ethiopia. Administrative Report. Addis Ababa; 2012.

55. Guintran J-O, Delacollette C, Trigg P. Systems for the early detection of malaria epidemics in Africa: an analysis of current practices and future priorities. Geneva: World Health Organization; 2006.

56. Wimberly MC, Midekisa A, Semuniguse P, Teka H, Henebry GM, Chuang T, et al. Spatial synchrony of malaria outbreaks in a highland region of Ethiopia. Trop Med Int Health. 2012;17:1192-201.

57. Gething PW, Atkinson PM, Noor AM, Gikandi PW, Hay SI, Nixon MS. A local space-time kriging approach applied to a national outpatient malaria data set. Comput Geosci. 2007;33:1337-50.

58. Tugume A, Muneza F, Oporia F, Kiconco A, Kihembo C, Kisakye AN, et al. Effects and factors associated with indoor residual spraying with Actellic 300 CS on malaria morbidity in Lira District, Northern Uganda. Malar J. 2019;18:44.

59. Tatem AJ. WorldPop, open data for spatial demography. Sci Data Nature Publishing Group. 2017:4:170004.

60. Dobson JE, Bright EA, Coleman PR, Durfee RC, Worley BA. LandScan: a global population database for estimating populations at risk. Photogramm Eng Remote Sens. 2000;66:849-57.

61. Kulldorff M. SaTScan TM User Guide. 2018.

62. Wan Z, Hook S, Hulley G. MOD11A2 MODIS/Terra land surface temperature/emissivity 8-day L3 global $1 \mathrm{~km}$ SIN grid V006. NASA EOSDIS Land Processes DAAC; 2015.

63. Schaaf C, Wang Z. MCD43C4 MODIS/Terra+Aqua BRDF/Albedo Nadir BRDF-Adjusted Ref Daily L3 Global 0.05Deg CMG V006. 2015;

64. Tucker CJ. Red and photographic infrared linear combinations for monitoring vegetation. Remote Sens Environ. 1979:8:127-50.

65. Gao BC. NDWI—a normalized difference water index for remote sensing of vegetation liquid water from space. Remote Sens Environ. 1996;58:257-66

66. Venables W, Ripley B. Modern applied statistics with S. 4th ed. New York: Springer; 2002

67. Huffman GJ, Bolvin DT, Nelkin EJ, Wolff DB, Adler RF, Gu G, et al. The TRMM multisatellite precipitation analysis (TMPA): quasi-global, multiyear, combined-sensor precipitation estimates at fine scales. J Hydrometeorol Am Meteorol Soc. 2007;8:38-55.

68. Mushinzimana E, Munga S, Minakawa N, Li L, Feng C, Bian L, et al. Landscape determinants and remote sensing of anopheline mosquito larval habitats in the western Kenya highlands. Malar J. 2006:5:13.

69. McFeeters SK. The use of the normalized difference water index (NDWI) in the delineation of open water features. Int J Remote Sens. 1996:17:1425-32.

70. Planet Team. Planet application program interface: in space for life on earth. San Francisco, CA; 2017.

71. Gorelick N, Hancher M, Dixon M, Ilyushchenko S, Thau D, Moore R. Google Earth Engine: planetary-scale geospatial analysis for everyone. Remote Sens Environ. 2017;202:18-27.

72. Dilts TE. Topography Tools for ArcGIS 10.1. University of Nevada Reno; 2015

73. Elith J, Graham CH. Do they? How do they? WHY do they differ? On finding reasons for differing performances of species distribution models. Ecography. 2009;32:66-77.

74. Elith J, Leathwick JR, Hastie T. A working guide to boosted regression trees. J Anim Ecol. 2008;77:802-13.

75. Friedman $\mathrm{JH}$, Meulman JJ. Multiple additive regression trees with application in epidemiology. Stat Med. 2003;22:1365-81. 
76. Hess A, Davis JK, Wimberly MC. Identifying environmental risk factors and mapping the distribution of West Nile virus in an endemic region of North America. GeoHealth. 2018;2:395-409.

77. Messina JP, Brady OJ, Golding N, Kraemer MUG, Wint GRW, Ray SE, et al. The current and future global distribution and population at risk of dengue. Nat Microbiol. 2019;1:1508-15.

78. Bhatt S, Gething PW, Brady OJ, Messina JP, Farlow AW, Moyes CL, et al. The global distribution and burden of dengue. Nature. 2013;496:504-504.

79. Dormann CF, Elith J, Bacher S, Buchmann C, Carl G, Carré G, et al. Collinearity: a review of methods to deal with it and a simulation study evaluating their performance. Ecography. 2013;36:27-46.

80. Ridgeway G, Southworth M, RUnit. Package 'gbm.' CRAN; 2013.

81. Hamza AM, Rayah EAE. A qualitative evidence of the breeding sites of Anopheles arabiensis patton (Diptera: Culicidae) in and around Kassala Town, Eastern Sudan. Int J Insect Sci SAGE Publications Ltd STM. 2016;8:IJIS.S40071.

82. Gone T, Balkew M, Gebre-Michael T. Comparative entomological study on ecology and behaviour of Anopheles mosquitoes in highland and lowland localities of Derashe District, southern Ethiopia. Parasit Vectors. 2014;7:483.

83. Ayele DG, Zewotir TT, Mwambi HG. Prevalence and risk factors of malaria in Ethiopia. Malar J. 2012;11:195-195.

84. Hwang J, Graves PM, Jima D, Reithinger R, Kachur SP, Group and the EMW. Knowledge of malaria and its association with malaria-related behaviors - results from the malaria indicator survey, Ethiopia, 2007. PLOS ONE Public Library of Science. 2010;5:e11692.

85. Zerdo Z, Bastiaens H, Anthierens S, Massebo F, Masne M, Biresaw G, et al. Long-lasting insecticide-treated bed net ownership, utilization and associated factors among school-age children in Dara Mallo and Uba Debretsehay districts, Southern Ethiopia. Malar J. 2020;19:369.

86. Paulander J, Olsson H, Lemma H, Getachew A, Sebastian MS. Knowledge, attitudes and practice about malaria in rural Tigray, Ethiopia. Glob Health Action Taylor \& Francis. 2009;2:1839.
87. Lyon B, Dinku T, Raman A, Thomson MC. Temperature suitability for malaria climbing the Ethiopian Highlands. Environ Res Lett. 2017; 12:064015-064015.

88. Lemma W, Alemu K, Birhanie M, Worku L, Niedbalski J, McDowell MA, et al. Anopheles cinereus implicated as a vector of malaria transmission in the highlands of north-west Ethiopia. Parasit Vectors. 2019;12:557.

89. Yukich JO, Taylor C, Eisele TP, Reithinger R, Nauhassenay H, Berhane $\mathrm{Y}$, et al. Travel history and malaria infection risk in a low-transmission setting in Ethiopia: a case control study. Malar J. 2013;12:33.

90. Asfaw W, Tolossa D, Zeleke G. Causes and impacts of seasonal migration on rural livelihoods: case studies from Amhara Region in Ethiopia. Nor Geogr Tidsskr. 2010;64:58-70.

91. Aschale Y, Mengist A, Bitew A, Kassie B, Talie A. Prevalence of malaria and associated risk factors among asymptomatic migrant laborers in West Armachiho District, Northwest Ethiopia. Res Rep Trop Med. 2018;9:95-101.

92. Alemu A, Tsegaye W, Golassa L, Abebe G. Urban malaria and associated risk factors in Jimma town, south-west Ethiopia. Malar J. 2011;10:173.

93. Nissen A, Cook J, Loha E, Lindtjørn B. Proximity to vector breeding site and risk of Plasmodium vivax infection: a prospective cohort study in rural Ethiopia. Malar J. 2017;16:380.

94. Kibret S, Wilson GG, Ryder D, Tekie H, Petros B. Malaria impact of large dams at different eco-epidemiological settings in Ethiopia. Trop Med Health. 2017:45:4-4.

95. Ijumba JN, Lindsay SW. Impact of irrigation on malaria in Africa: paddies paradox. Med Vet Entomol. 2001;15:1-11.

\section{Publisher's Note}

Springer Nature remains neutral with regard to jurisdictional claims in published maps and institutional affiliations.
Ready to submit your research? Choose BMC and benefit from:

- fast, convenient online submission

- thorough peer review by experienced researchers in your field

- rapid publication on acceptance

- support for research data, including large and complex data types

- gold Open Access which fosters wider collaboration and increased citations

- maximum visibility for your research: over 100M website views per year

At BMC, research is always in progress.

Learn more biomedcentral.com/submissions 